\title{
SCALING THE WALL: Factors Influencing the Conditions for Market Entry in the Mobile Data Market
}

\author{
Annemijn F. van Gorp \\ Carleen F. Maitland \\ Brian H. Cameron \\ School of Information Sciences and Technology \\ The Pennsylvania State University \\ University Park, PA U.S.A.
}

\begin{abstract}
Advances in mobile technology have created a fertile ground for the development of new and innovative information and entertainment services. However, the road from development to commercialization of these services is one that is currently under construction. In this research, we seek to understand the relationships between developers of information services and the powerful mobile network operators that dominate the industry, which in turn shed light on the forces shaping the diversity of information sources on the mobile Internet. To understand these relationships, we have undertaken a research project in which we follow the attempts of a small firm to commercialize their information service in the United States. The project combines knowledge of industry structures with the first-hand market entry experience of a small firm. Results derived from the application of an institutional economics theoretical lens indicate that informal institutions, technology, and market power have combined to create the context for mobile services provision, which can be characterized as a highly fragmented market. This market fragmentation, together with technology, market power, and informal institutions, defines the choices application developers must make and indirectly determines the developers who will and will not be able to enter the market.
\end{abstract}

Keywords Mobile application provision, J2ME, BREW, business model, market structure 


\section{INTRODUCTION}

Internet technologies make possible the sharing of information between widely diverse sources and audiences. With the fixed Internet, the provision of this information is undertaken on both commercial and noncommercial bases. For some information suppliers, the choice to provide information on a noncommercial basis is a result of underdeveloped payment systems. On the mobile Internet, the operator's control of the network infrastructure and ownership of the customer relationship resolves this payment dilemma as long as the information provider is willing to conform to the technical and administrative requirements of these powerful players. Thus, through control and ownership, operators are potentially in a position to influence the information made available to consumers.

In this research, we seek to understand the relationships between providers of information services and the powerful mobile network operators that dominate the industry, as well as the subsequent effects of these relationships on diversity of information sources. At the outset of the mobile Internet industry, there was speculation of two likely outcomes. One outcome would be a mobile Internet industry where the network operators would maintain their dominance and serve as gatekeepers for mobile Internet content. The second outcome would be an industry where powerful content providers would turn the network operators into "bit pipes," limited to merely transmitting a wide variety of content. In the current early stages of industry development in the United States it appears the first outcome has taken hold. Mobile operators or intermediaries serve as gatekeepers for the information that is available to mobile Internet users. This leads to the following questions: How have such developments on the distributors' side influenced the conditions for market entry for application developers? How do firms who want to make content and applications available to mobile consumers operate in this environment? What are the resultant incentives and disincentives for market entry?

To understand the forces at work, we employ an institutional economics theoretical framework and combine knowledge of industry structures with information gained from observing the market entry experience of a small firm. The goal of this exercise is first to confirm the hypothesized role played by technology and firm strategies and, if justified, to more clearly understand the interactions between the factors. These findings will provide a more clear understanding of the implications of the current environment in the U.S. mobile industry for information diversity.

\section{INSTITUTIONS AND TECHNOLOGICAL CHANGE}

In the field of new institutional economics, institutions are considered the humanly derived constraints that shape human interaction and have been compared to the rules of a game (North 1990). As with game playing rules, institutions are both formal and informal and shape the behavior of individuals as well as the strategies employed by teams (organizations). Applied to firms and markets, institutional theory has been used to describe the interaction between formal institutions, such as laws and regulations, and 
informal institutions, such as norms of particular contexts, in shaping firm behavior and strategies (e.g., Alston et al. 1996). The number of studies performed on informal institutions is relatively small and they are primarily concerned with economic development. Among the few that focus on the firm, the emphasis is on entrepreneurship: they examine the role of informal institutions in enforcing property rights when formal institutions are vague (Peng 2004), and the presence and absence of the influence of social norms and relationships in entrepreneurial activity (Frederking 2004). In a departure from these studies, which consider the broad gap between national legal structures (formal institutions) and social norms (informal activities), we cover a middle ground. This middle ground consists of the area where national legal frameworks do not apply; however, powerful firms have created the rules for market entry, which we consider informal institutions.

A significant force in the mobile industry influencing informal institutions is technology. As discussed by Arthur (1989) and David (1985), technological change is path dependent and, particularly with network technologies, lock-in can occur. Thus, the set of mobile technologies that exists today is the result of related events and technology choices made in the past. Furthermore, lock-in can serve as a significant source of power for a firm. Indeed, as noted by North (1990), competition among technologies is based more on the traits of the firms representing the technologies than on the technologies themselves.

In addition to technology, the study of firm behavior must also consider firmspecific factors (De Vlaam and Maitland 2003; Oliver 1991). Firm-specific factors of interest here are the ownership and use of resource asymmetries, particularly in relation to access to network infrastructure, information, and consumers. As explained by Barney (1986), in strategic factor markets, firms acquire resources that are used to implement strategies in product markets. However, the only way, other than blind luck, to obtain competitive advantage from these resources is to have more accurate expectations (information) about their value to the firm. However, if the new resource is rare, inimitable, and non-substitutable, this will influence the firm's strategy in obtaining the resource (Makadok and Barney 2001). This insight has implications for the relationship between developers and mobile operators, who in providing access to customers offer a fairly rare and inimitable resource. Furthermore, these concepts also provide a basis for comparing our results with those from other markets.

To understand the costs and benefits to market entry faced by developers we propose to link the concepts of technology, strategy, institutions, and the conditions for market entry in the following way (see Figure 1). First, we propose that technologies of the mobile industry influence the strategies pursued by mobile industry distributors, which include operators as well as intermediaries, as regards managing consumer applications and content. This relationship is symbiotic and hence the influence is bidirectional. The technology and strategy combine to create the rules of the game that are the informal institutions. The informal institutions, in turn, create a part of the market entry context for developers. ${ }^{1}$

'The arrows in Figure 1 are meant to indicate influence only and do not imply causality. 


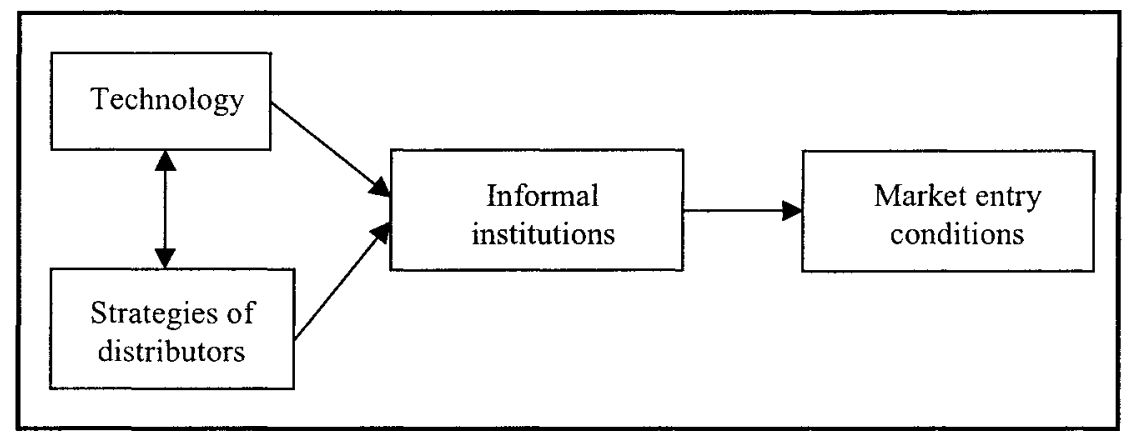

Figure 1. Conceptual Model

We begin with a general description of mobile Internet technologies and distribution strategies, followed by a description of the informal institutions faced by developers and the resultant conditions of market entry. The paper concludes with analysis and discussion of the role that technology and the strategies of powerful distributors play in defining the informal institutions of the market and their implications for the diversity of types of firms, and hence content, represented on the mobile Internet.

\section{TECHNOLOGICAL BACKGROUND OF THE MOBILE INTERNET AND DISTRIBUTION STRATEGIES}

To understand the strategic choices of operators and application developers, it is first necessary to understand the context within which they operate. We first provide an overview and background on the mobile Internet industry before we continue with a discussion about the technologies and the strategies by various players that together are shaping the industry.

\subsection{Technologies in the U.S. Market}

The U.S. market for mobile services is dominated by five national operators: Verizon Wireless, Cingular/AT\&T Wireless, Sprint, Nextel, and T-Mobile. Cingular, with its recent acquisition of AT\&T Wireless, is the current market leader with 47 million customers. It is followed by, respectively, Verizon Wireless (42 million), Sprint PCS (22 million), T-Mobile (16 million), and finally Nextel (15 million). ${ }^{2}$

${ }^{2}$ From "Largest Mobile Telephone Companies" (http://en.wikipedia.org/wiki/Largest_ mobile_phone_companies). 
For the past four years, all of the operators ${ }^{3}$ have been busy managing the transition from the comparatively simple business of offering voice services to the rather complicated business of mobile data services provision. For these operators, mobile data provision includes both managing significant infrastructure upgrades as well as managing the provision of content and applications. These changes have presented a market entry opportunity for stand-alone content and application providers that provide services to end-users on either a commercial or noncommercial basis.

\subsubsection{The Mobile Internet}

Before continuing this discussion, we first need to define the term mobile Internet. Mobile Internet actually refers to two types of data networks: intranet as well as true Internet. First, all mobile operators provide their own proprietary data services, which typically entail services such as ringtones, instant messaging, games, news services, email, and other applications. We may perceive such service offerings as large intranets (a.k.a. the "walled garden"), as only the particular operator's customers may access these services.

The majority of operators provide browsing capabilities as well. To this extent, end-users may browse to sites hosted on servers outside the operator's domain (intranet). These sites are typically based on WAP (wireless access protocol), a standard that is supported by the majority of phones nowadays and which enables the display of text on mobile phones. We might call these true mobile Internet services, as anyone with a WAP-supported phone may access these sites, while at the same time anyone may host a WAP page on a server. Mobile users may browse to the WAP page or may find it by using, for example, Google's mobile search engine. However, one issue coming into play is that operators may inactivate browsing functions on mobile phones, or that they may require subscription to their proprietary services via which end users then access browsing functions. For example, Cingular Wireless provides free browsing services where the end user just pays per $\mathrm{KB}$ download, while Verizon Wireless requires paid subscription to its GetItNow portal via which end-users then access the browsing function. On top of the GetItNow subscription, they need to pay for downloading time as well. Thus, operators, through their subscription services, are still largely in control of whether, and how, customers may access these mobile Internet services.

Besides operators' control through subscription services, another constraining factor in further development of the true mobile Internet concerns the lack of widely accepted, independent payment mechanisms. In the current dominant model, end users pay the operator for all services, and the operator in turn pays the content or application provider. This means that for all commercial purposes, the content or application provider is required to offer services via operators' proprietary intranets.

${ }^{3}$ Here we focus on the dominant national operators. There are approximately 100 additional small operators but they have yet to provide an additional outlet for content and applications. 


\subsubsection{Wireless Platforms}

The development of the mobile Internet will also depend on the underlying technologies. While technologies such as wireless access protocol (WAP), short message service (SMS), and the related multimedia message service (MMS) are available on nearly all handsets, the dominant technology for more advanced applications has yet to be decided. The two contenders are Java 2 Platform, Micro Edition (J2ME) and Binary Runtime Environment for Wireless (BREW). These competing technologies allow for the development of more advanced applications, enabling color display, sound, interactivity, etc. BREW is a proprietary platform developed by QUALCOMM, while $\mathrm{J} 2 \mathrm{ME}$, which is an optimized Java runtime environment, is an open standard. Mobile devices supporting J2ME are unable to execute BREW applications. However, devices supporting BREW are able to execute J2ME applications with special software. Nevertheless, this is a development only recently introduced and not pervasively marketed as yet. Formerly, BREW-capable phones were only able to execute BREW in itself.

While BREW's use by developers has been limited, J2ME has experienced widespread use, due in part to the prevalence of Java, an open standard, as a development tool for a variety of desktop and server applications. The widespread availability of J2ME applications has created more choice and often better prices (sometimes even free) for end-users. With experienced Java programmers around every corner, developing in BREW incurs greater costs in adjusting to the platform. However, these negative consequences for BREW development have led to the introduction of software, making BREW more easily compatible with J2ME. ${ }^{4}$ However, operating in both environments is not as simple as merely translating the software as each technology is associated with different operators or intermediaries, each with their own processes and procedures and business models. Thus, the choice of platform technology is a complicated one, best made early in the development cycle.

The lack of uniform standards in technology makes access to mobile services more complicated: (operator specific) devices typically support only a few platforms, and thus limit the end-user's access to only content and application services based on those particular platforms. While J2ME and BREW are inherently distinct programming platforms, and developers may want to value them in terms of costs of development tools, access to information, speed of execution, power of available APIs, etc., debates with proponents for both standards indicate they provide rather similar capabilities.

${ }^{4}$ For example, BREW2Bridge entered the market in 2003, allowing developers to download tools that let them build BREW applications by using Microsoft Visual Studio. NET or J2ME, thus helping developers avoid rewriting applications for various operator or handset specific requirements. Additionally, BREW2Bridge enables the running and testing of J2ME applications on BREW-enabled platforms. However, the developer needs a BREW-enabled Java virtual machine (JVM) to run the tool, as without the JVM one is unable to run the J2ME application in the BREW emulator or download the J2ME application to the phone. These tools are all available for download at the QUALCOMM/BREW Web site. Furthermore, Emertec's Geode and IBM's J9 allow for BREW-compatible JVMs. However, they are not yet available for purchase. 
Nevertheless, a study by Zelos Group Inc in June 2004 predicts that 90 percent of a projected 100 million mobile devices between now and 2009 will contain either BREW or Java (J2ME), with Java remaining the dominant platform. Furthermore, regardless of Java's projected dominance, Zelos Group points out that Java's openness is actually limiting its evolution, because of lengthy community consensus building processes. The proprietary standard of BREW may, therefore, allow for easier technological advance. This is in line with a more often heard argument that, in mobile space, proprietary solutions have been more effective in creating markets for content, data, and billing. While we cannot look into the future, such debates point out that while technological characteristics are important, it is also important to recognize the link between the technologies and the business models of the organizations who champion them.

\subsection{Distributors' Mobile Strategies}

Along with these platform technology choices, the provision of mobile content and applications will be greatly influenced by the business strategies pursued by operators as well as intermediaries (content aggregators that bring developers and operators together). A business model may be identified as the organization of product, service, and information flows, as well as the sources of revenues and benefits for both suppliers and customers (Timmers 1998). Furthermore, while not explicitly considered in many business model studies, a business model is seen as being inextricably linked to new technologies (Hawkins 2002). In the mobile industry, business models are largely driven by operators who organize networks of service providers to fill the roles required to offer complex services (Maitland et al. 2005). The networks differ in the way roles are distributed throughout the network and, in particular, in the degree that operators choose to outsource or internally manage content and quality control. These strategies have important implications for application developers and content providers in their market entry attempts. Table 1 provides a short overview of these characteristics, which are discussed below.

\subsubsection{Content Control}

The degree to which operators manage content internally differs greatly. To this extent, the relationships with developers are of great importance. Relations with developers are by all operators maintained through so-called developer zones, which is a virtual community platform (on the Internet) through which developers commercialize their applications. All contact regarding the full commercialization process between potential developers and operator or intermediary occurs through these developer zones. These provide, among others, information on programming requirements, discussion forums for information exchange among developers themselves and between developer and operator or intermediary, services for uploading applications, etc.

Some operators, namely AT\&T Wireless, Cingular (partly), Verizon Wireless (only for WAP based services), and T-Mobile, manage their own developer zones, and therefore a direct relationship with developers. This means that operators are in full control 
Table 1. Operator's Mobile Strategies

\begin{tabular}{|c|c|c|c|c|}
\hline Operator & \begin{tabular}{|c|} 
Name \\
Service/ \\
Virtual Store
\end{tabular} & $\begin{array}{l}\text { BREW/ } \\
\text { J2ME }\end{array}$ & $\begin{array}{c}\text { Developer Zones: } \\
\text { In-house/ } \\
\text { Outsourced }\end{array}$ & $\begin{array}{c}\text { Testing: } \\
\text { In-house/ } \\
\text { Outsourced }\end{array}$ \\
\hline Cingular & MEdia Net & J2ME & $\begin{array}{l}\text { In-house developer } \\
\text { zone: Cingular } \\
\text { Wireless Developer } \\
\text { Program } \\
\text { - Outsourced: Cell- } \\
\text { mania developer } \\
\text { zone for Cingular }\end{array}$ & $\begin{array}{l}\text { - CWDP: N/A } \\
\text { - Cellmania: } \\
\text { developers testing } \\
\text { themselves }\end{array}$ \\
\hline $\begin{array}{l}\text { AT\&T } \\
\text { Wireless }\end{array}$ & mMode & J2ME & In-house: devCentral & $\begin{array}{l}\text { - WAP: developers } \\
\text { testing through } \\
\text { AT\&T's WAP } \\
\text { gateway } \\
\text { J2ME: } \\
\text { Outsourced to } \\
\text { VeriTest }\end{array}$ \\
\hline $\begin{array}{l}\text { Verizon } \\
\text { Wireless }\end{array}$ & GetItNow & BREW & $\begin{array}{l}\text { - In-house (WAP): } \\
\text { The Zôn } \\
\text { - Outsourced } \\
\text { (BREW): } \\
\text { QUALCOMM }\end{array}$ & $\begin{array}{l}\text { WAP (The Zôn): } \\
\text { N/A } \\
\text { BREW } \\
\text { (QUALCOMM): } \\
\text { NSTL }\end{array}$ \\
\hline $\begin{array}{l}\text { Sprint } \\
\text { PCS }\end{array}$ & $\begin{array}{l}\text { Sprint PCS } \\
\text { Vision }\end{array}$ & $\mathrm{J} 2 \mathrm{ME}$ & $\begin{array}{l}\text { - Partly in-house: } \\
\text { Sprint Application } \\
\text { Developers' Pro- } \\
\text { gram (registration } \\
\text { only) } \\
\text { - Partly outsourced: } \\
\text { Formerly to } \\
\text { Handango, cur- } \\
\text { rently searching for } \\
\text { new solution }\end{array}$ & N/A \\
\hline T-Mobile & T-Zones & $\mathrm{J} 2 \mathrm{ME}$ & $\begin{array}{l}\text { In-house: T-Mobile } \\
\text { Developer Center }\end{array}$ & $\mathrm{N} / \mathrm{A}$ \\
\hline Nextel & & $\mathrm{J} 2 \mathrm{ME}$ & $\begin{array}{l}\text { Outsourced: } \\
\text { Cellmania (specific } \\
\text { developer zone for } \\
\text { Nextel) }\end{array}$ & $\mathrm{N} / \mathrm{A}$ \\
\hline
\end{tabular}


of what services will become available and in which manner (e.g., software specifications, revenue streams, etc.). However, Verizon Wireless (applications in BREW format), Cingular (partly), Sprint PCS (partly), and Nextel have outsourced the management of their developer zones to other organizations. For BREW, as a proprietary standard, services may only be developed for, and distributed by, its patent holder, QUALCOMM. Therefore, for Verizon Wireless' BREW applications, developer relationships are inherently maintained by QUALCOMM. Rather similar intermediaries for J2ME development exist, however they do not have strict business models related to technology such as BREW. Operators may outsource any part of their operations voluntarily. For example, Cingular and Nextel have developer zones managed by Cellmania. Sprint PCS has recently ceased its cooperation with Handango, which used to be the primary aggregator and manager for all of its J2ME applications. Additionally, Sprint PCS maintained its own developer zone by which it maintained contact with developers. Sprint PCS is now searching for a new partner.

The parties to which developer zones are outsourced gain great influence on which applications to accept. QUALCOMM, for example, aggregates all of the applications from which the operator then may choose. Additionally, the operator will negotiate with the developers, and thus still has influence on the relationship, however not specifically on which applications are accepted in the first instance. While Cellmania has developer zones specifically targeted toward a particular operator (i.e., Cingular and Nextel), it is not clear whether it also performs all negotiations, or whether the operator still takes responsibility for this part of the process.

In addition to the potential outsourcing of developer relations, the majority of operators have agreements with so-called publishers and other third parties providing application directories as well. For example, Handango cooperates with all large operators except for Nextel. These publishers make agreements with developers and maintain their applications, as well as guide them through the negotiation process with operators. For operators, publishers provide easy access to thousands of applications from which to choose without having to deal with the complete commercialization process through which developers need to go. These relations are generally maintained in addition to the operators' own (or outsourced) developer zone relationships.

Finally, a last potential source of cooperation for operators constitutes the so-called application directory services as provided by third parties. For example, mFinder and $\mathrm{J} 2 \mathrm{ME} \mathrm{mFinder}$, provided by Cellmania, are large directories containing thousands of applications. After initial agreements between operator and third party provider to establish access to such directories, operators' customers enter the directoriescompletely owned and managed by a third party - remotely to find applications of their choice. In this case, no further agreements between operator and application provider exist at all. Here the operator loses complete control over services provision aside from the potential influence on directory providers' business strategies.

\subsubsection{Quality Control: Testing Programs}

In addition to content control and related business models, the testing of applications can be perceived as an important part of the process of commercialization 
of applications. While typically strict requirements are already set for software creation itself, additional testing takes place before applications are accepted in virtual stores. This is performed as perceived necessary by operators or intermediaries. Different testing procedures are in place. First, after testing an application on the developer's own workstation, the developer may have to upload it to the intermediary or operator of choice with which certain agreements have been reached. The latter then either outsources the testing, or performs the testing in-house. Also, in some cases, developers test their applications themselves, using specific directions as provided on the respective developer zones. A third possibility is the requirement for a developer to obtain a testing certificate from a specified software testing company. In this case, the operator is not at all involved in the testing procedure, except for setting requirements. Major software testing companies are NSTL and VeriTest, who serve respectively QUALCOMM and AT\&T Wireless. In the case of QUALCOMM, developers just need to show their certificate. They pay the testing fee themselves.

Outsourced testing will lead to high quality levels and reliability: applications are generally tested on a host of devices as well as to networks, and thus assure great interoperability. If a developer has to do the testing personally, typically only one device may be available. Professional testing, however, does add to the costs of commercializing applications. It is unclear how these costs are precisely covered, but often we found that developers have to pay for the testing in order to become part of an operator's alliance network. These few hundred dollars extra costs make it more difficult for especially smaller developers to commercialize their applications. However, it ensures that end users will receive reliable services.

\subsection{Interaction: Technology and Distributors' Strategies}

The discussion above shows that technology and business model may be highly intertwined. Dependent on the application platform-BREW or J2ME - particular business models may develop. As was already touched upon, BREW means more than just a technological standard. It is both a standard and business model, owned and patented by QUALCOMM. This has limited BREW-based services to only be developed for and distributed by QUALCOMM.

In the United States, Verizon Wireless is the only operator using the BREW standard and business model, whereas all other major operators employ applications based on the open-standard J2ME. As a result, a smaller variety of BREW applications is available, and in the United States only accessible by Verizon Wireless' customers. Verizon Wireless, therefore, has been able to develop a very close relationship with QUALCOMM. This means that Verizon Wireless has great control over development of BREW as a standard, and the way BREW applications are brought to the market.

On the contrary, J2ME does not determine a specific business model. Moreover, the degree of control over technology by the operators using J2ME is significantly smaller, as it is an open standard. Regardless, we can see that the market has led to certain outcomes of service offerings. First, as we have seen, use of proprietary data services (referred to earlier as intranets) remains common across all operators, whether operators employ BREW or J2ME. The main difference lies in the fact that, on the 
wider (mobile) Internet, many $\mathbf{J} 2 \mathrm{ME}$ applications are available to download independent of any operator. While end users may find these by themselves through search engines or browsing, large directories as provided by Cellmania (J2ME mFinder), for example, seem to be the most common modes for access. With these directories being the result of closed data networks and proprietary information services, the providers of these directories have taken on an important role in the market. In many cases they have been able to take control over operators' virtual stores or wireless portals (the customer's entry point to the mobile Internet). This is much like the case of Verizon Wireless' GetItNow portal being powered by BREW, even though the latter is a requirement coming along with the BREW business model. In more detail, if we look at J2ME application provision, we see that Cellmania powers the Nextel Store as well as Cingular's Wireless Software Store, while Handango formerly took care of Sprint PCS Vision. This implies that these third parties are taking over the operator's control of available content and applications, to some extent, as well as gaining more influence on quality assurance, as developers typically submit their applications to these third parties.

These developments lead to a couple of insights. First, while BREW technology has created a relatively strictly controlled market for application development, J2ME development remains very open. Second, in relation to business model development, we find that the BREW standard has allowed for greater quality assurance, as very specific testing procedures are in place. While for J2ME this part remains open to the operator or intermediary, no uniform quality standard has been set. While it does not necessarily mean lower quality, it has led to a lower level of control over quality.

\section{INFORMAL INSTITUTIONS AND MARKET ENTRY CONDITIONS}

The mobile Internet market entry conditions for application and content developers will be shaped by general economic factors, such as the availability of venture capital and labor market conditions, as well as factors specific to the mobile industry itself. Here we are concerned with the latter, and consider these factors to include both the informal institutions or rules as well as some more general market conditions that are the result of technologies and strategies pursued by distributors.

\subsection{Informal Institutions in the Mobile Internet Industry}

The interdependence of technology and strategies of distributors creates a variety of rules that influence all aspects of the application and content developers' market entry decisions. The rules are grouped into two classes that vary in terms of their implications for the role of the distributor in the business of the developer.

In the first class of rules, the distributor has significant influence. One rule in this class is whether or not approval for a product/service concept is required. Whether or not this rule applies depends on a developer's choice of distributor. Furthermore, approval may go beyond the distributor's product concept to include an assessment of 
the developer's financial standing. A second rule is whether or not the developer will have to use third-party testing, which in turn specifies the testing organization and reduces a developer's control over costs and time to market.

In the second class of rules, there are less severe control implications. One such rule is the requirement to meet technical specifications for an application as defined by the distributor. These specifications typically include requirements for self-testing, as well as terms and conditions for access to reduced cost testing subscriptions that allow developers to test applications on several phone models. A second rule is agreeing to the terms and conditions of the revenue sharing agreement, which are usually specified by the distributors. A third set of rules developed by distributors governs access to technical and business process assistance. These rules are typically codified and enforced in the developer zones. While some distributors make support freely available, others create special categories of support which developers can buy into.

While these rules demonstrate the results of the interaction of technology and strategies pursued by distributors, they are certainly not an exhaustive list. Neither are they the sole determinant of market entry conditions. Below we discuss how these rules and the industry characteristics resulting from technologies and strategies combine to create a partial picture of the market entry conditions.

\subsection{Market Entry Conditions}

Market entry conditions are of interest because they influence entrepreneurs' decisions of whether to enter a market or put their resources to other uses. In this case, we are interested in the market entry conditions encountered by developers as compared to those firms who have made content and applications available on the fixed Internet. For the mobile Internet, we have found that the implications of technology and business strategy can be characterized as five effects, which we describe here.

The first effect is related to the concept of the strategic factor market. As compared to other industries (for example, retail outlets), developers have a fairly limited number of distributors through whom they can gain access to customers. Furthermore, circumventing these distributors by approaching customers directly, which is possible due to the Internet technology, results in great challenges for managing payments.

The second effect concerns the fragmentation of platform technologies and how they limit developers' access to particular market segments. In choosing a platform technology, the developer chooses the market segment served by the operators supporting that technology.

The third effect is the result of agreements between operators and intermediaries. Agreements between operators and intermediaries include those concerned with operating developer zones as well as managing content control. In addition to specifying the terms and conditions of access to these services by developers, developers are also affected by the stability (or lack thereof) in the intermediary/operator relationship.

The fourth and fifth effects are trade-offs. Developers encounter the fourth effect in their decision to purchase access to customers directly through an operator or through an intermediary. In this decision, developers face a trade-off between being close to customers, which is typically achieved through an operator, versus ease of the commer- 
cialization process, which typically faces fewer barriers with an intermediary. A similar trade-off is experienced in the area of quality control. Whereas aligning with a distributor with strict quality control requirements creates greater costs, it also establishes higher quality of all offerings and can attract more customers.

These market conditions, in combination with the rules faced by developers, will influence their decisions on when or whether or not to enter the market. What we see is that the market conditions include a fragmented industry with competing technologies and mechanisms that challenge the ability of developers to maintain control over the process of commercialization. These conditions may make entry for de novo entrants, new firms unaffiliated with existing firms, difficult. These conditions can be compared with the relatively easy market entry conditions faced by entrepreneurs wanting to place content and applications on the fixed Internet. However, while the processes for delivering content and applications for these firms may have been and continue to be much simpler, the ability to collect payment has presented its problems.

\section{CONCLUSIONS}

As the discussion of informal institutions and conditions for application developers' market entry highlights, the market for mobile data services has been shaped to a large extent by a complex interaction between technology and distributors' strategies. In this research, we set out to answer a set of questions related to the development of the industry and its implications for the provision of applications and content in the mobile Internet.

Developments in the market on the distributors' side have provided for a relatively small number of national operators to gain significant market power, which has enabled operators to influence the development of the industry's informal institutional context. Distributors' significant control over content and quality has set the rules of the game for developers' commercialization of application services. The multiple platform technologies have created a fragmented market for application and content. In this situation, application developers must choose simultaneously a platform technology and a distributor with whom to align. The choice of distributor will also determine the rules the application developer must follow to enter the market. These rules, similar to the informal institutions discussed by Peng (2004) and Frederking (2004) create costs and benefits for market entry. Thus, this research contributes to the literature on informal institutions by extending the conceptualization of informal institutions from norms and social ties to further include the rules and regulations created by powerful firms.

While developers wield some power in being able to choose among different institutional contexts by choosing operators, and hence presumably may influence unfavorable rules through defection, the large number of application developers and their relatively low market power leaves them as takers rather than makers of the institutional context. Even as the intermediaries might begin to challenge the market power of the operators, it is unclear the extent to which they will be able to follow through. Trends of consolidation among the operators-Cingular's recent acquisition of AT\&T Wireless as well as the likely future merger between Sprint PCS and Nextelfavor a further consolidation of power in this realm. 
Naturally the power structure created by a small number of national operators versus a large number of developers, has both positive and negative consequences. The ability of operators to create an institutional context that enhances quality and interoperability through strict testing requirements has benefits for testing firms as well as for consumers. However, it also implies stricter control on availability of specific information services by the operators. Additionally, we may argue that the terms and conditions for market entry will influence the types of firms that can incur the costs created by the institutional environment. Trends in this institutional environment suggest that established firms with sound financial histories will be welcome, while start-ups may find market entry more difficult. This, combined with the fragmented nature of the industry which provides incentives for developers to make multiple offerings, suggests that the industry may evolve to include a few developers and content providers that provide a large share of the applications and content for the mobile Internet. We can only ask ourselves if, in such an environment, fixed Internet innovations such as blogs could emerge. Additionally, we may ask what consequences these current market developments have on service for consumers in underrepresented groups, such as minorities and rural users. It could very well be possible that larger firms will be forced to develop for the average user, thereby affecting the diversity of services.

\section{ACKNOWLEDGMENTS}

This research was made possible, in part, by a grant from AT\&T Wireless. The authors wish to thank Lloyd Holder and Glenn Greenblatt of NSTL Inc. for valuable insights into the evolution of the mobile industry.

\section{REFERENCES}

Alston, L. J., Eggertsson, T., and North. D. (Eds.). Empirical Studies in Institutional Change, Cambridge, UK: Cambridge University press, 1996.

Arthur, W. B. "Competing Technologies, Increasing Returns and Lock-in by Historical Events," The Economic Journal (99:394), 1996, pp. 116-131.

Barney, J. B. "Strategic Factor Markets: Expectations, Luck, and Business Strategy," Management Science (32:10), 1986, pp. 1231-1241.

David, P. "Clio and the Economics of QWERTY in Economic History: A Necessary Though Not Sufficient Condition for an Economist," The American Economic Review (75:2), 1985, pp. 332-337.

De Vlaam, H., and Maitland, C. F. "Competitive Mobile Access in Europe: Comparing Market and Policy Perspectives," Communications \& Strategies (50), 2003, pp. 69-96.

Frederking, L. C. "A Cross-National Study of Culture, Organization and Entrepreneurship in Three Neighborhoods," Entrepreneurship and Regional Development (16:3), 2004, pp. 197215.

Hawkins, R. "Do Business Models Matter?," position paper presented to the International BITA B4U Workshop, Business Models for Innovative Mobile Services, Delft, The Netherlands, November 15-16, 2002.

Maitland, C. F., Van de Kar, E. A. M., Wehn de Montalvo, U., and Bouwman, H. "Mobile Information and Entertainment Services: Business Models and Service Networks," International Journal of Management and Decision Making (6:1), 2005, pp. 47-64. 
Makadok, R., and Barney, J. B. "Strategic Factor Market Intelligence: An Application of Information Economics to Strategy Formulation and Competitor Intelligence," Management Science (47:12), 2001, pp. 1621-1638.

North, D. C. Institutions, Institutional Change and Economic Performance, Cambridge, UK: Cambridge University Press, 1990.

Oliver, C. "Strategic Responses to Institutional Processes," The Academy of Management Review (16:1), 1991, pp. 145-179.

Peng, Y. "Kinship Networks and Entrepreneurs in China's Transitional Economy," The American Journal of Sociology (109:5), 2004, pp. 1045-1075.

Timmers, P. “Business Models for Electronic Markets," Electronic Markets (8:2), 1998, pp. 3-8.

\section{ABOUT THE AUTHORS}

Annemijn van Gorp is a Ph.D. candidate in the School of Information Sciences and Technology at the Pennsylvania State University. She has a M.Sc. degree in Systems Engineering, Policy Analysis and Management from Delft University of Technology in the Netherlands. Annemijn's research interests include the effect of market structure, competition, and policy on the provision of both fixed and wireless broadband Internet access services, as well as the changing roles of national, regional and international institutions in the provision of telecommunications services. Annemijn can be reached at avangorp@ist.psu.edu.

Carleen Maitland is an assistant professor in the School of Information Sciences and Technology at the Pennsylvania State University. She received a doctorate in 2001 from Delft University of Technology in the Netherlands, where she was an assistant professor prior to joining Penn State. She also holds M.S. (Stanford University) and B.S. (Worcester Polytechnic Institute) degrees in engineering and served as a Peace Corps Volunteer in Malawi, southern Africa. Carleen's research interests include the effects of new mobile and wireless technologies on organizations and industry structure, as well as the role of national policies in bringing about these effects. She has published in journals such as Telecommunications Policy, Information Economics and Policy, and Communications and Strategies. Carleen can be reached at cmaitland@ist.psu.edu.

Brian H. Cameron is an assistant professor of Information Sciences and Technology at the Pennsylvania State University. Prior to joining Penn State, he was Director of Information Technology for WorldStor, Inc., a storage service provider (SSP) in Fairfax, VA. As director of IT, Brian was responsible for designing and building the company's national IT infrastructure. He designed and managed the implementation of the corporate network infrastructure and also managed the implementation of a $\$ 3.5$ million ERP/CRM system. He has also held a variety of technical and managerial positions with IBM and Penn State. Brian has his Ph.D. and MBA from Penn State. His primary research and consulting interests include enterprise systems integration, storage networking, emerging wireless technologies, and the use of simulations and gaming in education. He has designed and taught a variety of courses on topics that include networking, systems integration, storage networking, project management, and IT consulting. Brian can be reached at bcameron@ist.psu.edu. 